\title{
Evaluation of velvet antler total protein effect on bone marrow-derived endothelial progenitor cells
}

\author{
XIANG XIAO ${ }^{1 *}$, LIN LI $^{2 *}$, SHUQIANG XU ${ }^{3}$, MIN MAO $^{4}$, RUIYAN PAN $^{5}$, \\ YANJUN LI ${ }^{1}$, JIAYUN WU $^{1}$, LI HUANG $^{2}$ and XIAOYUN ZHENG ${ }^{6}$ \\ ${ }^{1}$ Graduate School, Beijing University of Chinese Medicine; ${ }^{2}$ National Integrated Traditional and Western \\ Medicine Center for Cardiovascular Disease, China-Japan Friendship Hospital, Beijing 100029; ${ }^{3}$ Emergency \\ Office, National Health and Family Planning Commission of the People's Republic of China, Beijing 100044; \\ ${ }^{4}$ Pharmaceutical Department, China-Japan Friendship Hospital; ${ }^{5}$ Department of Pharmacology, Beijing \\ Anzhen Hospital, Capital Medical University, Beijing Institute of Heart Lung and Blood Vessel Diseases; \\ ${ }^{6}$ Department of Senior Official Ward, China-Japan Friendship Hospital, Beijing 100029, P.R. China
}

Received February 10, 2017; Accepted July 3, 2017

DOI: $10.3892 / \mathrm{mmr} .2017 .7019$

\begin{abstract}
Lu Rong, velvet antler (VA), is a traditional Chinese medicine, which is used as a food supplement and therapeutic drug in China, Japan, Russia, New Zealand and Southeast Asia. The regenerative characteristics of VA have resulted in great research interest, particularly regarding the fields of organ grafting and stem cell differentiation. Various VA proteomic studies verified that proteins act as the primary bioactive components of VA. The present study aimed to investigate if VA proteins (VA-pro) influence endothelial progenitor cell (EPC) viability. Various methods have previously been used to investigate VA-pro, including freeze-drying technology, ultrasonic wave methods, high performance liquid chromatography-mass spectrometry, EPCs extraction and
\end{abstract}

Correspondence to: Professor Li Huang, National Integrated Traditional and Western Medicine Center for Cardiovascular Disease, China-Japan Friendship Hospital, 2 Yinghua Dongjie, Chaoyang, Beijing 100029, P.R. China

E-mail: lihstrong@163.com

Professor Xiaoyun Zheng, Department of Senior Official Ward, China-Japan Friendship Hospital, 2 Yinghua Dongjie, Chaoyang, Beijing 100029, P.R. China

E-mail: atfen@126.com

*Contributed equally

Abbreviations: VA, velvet antler; VA-pro, velvet antler proteins; GO, Gene Ontology; KEGG, Kyoto encyclopedia of genes and genomes; pI, Protein isoelectric point; MW, proteins molecular weight; CMECs, cardiac microvascular endothelial cells; IH, ischemia hypoxia; MMP, mitochondrial membrane potential; CD31, Platelet endothelial cell adhesion molecule-1; vWF, von Willebrand factor; CVD, cardiovascular disease

Key words: velvet antler, endothelial progenitor cell, proliferation, migration, notch, Akt culture. Results demonstrated that VA-pro promoted EPCs proliferation and migration, particularly at a concentration of $1 \mathrm{mg} / \mathrm{ml}$. Furthermore, VA-pro increased the activation level of Notch1 intracellular domain and Hes1, and the level of phosphorylated-Akt and phosphorylated-mechanistic target of rapamycin. VA-pro may therefore affect EPC viability via regulation of the Notch and Akt signaling pathways. The present study revealed the effects and potential molecular mechanism of VA-pro on EPCs, and suggested an association between VA regeneration characteristics and the optimization of EPC viability. These findings may contribute to EPC transplantation research and aid in providing a novel treatment method for vascular diseases in the future.

\section{Introduction}

Endothelial progenitor cells (EPCs), also called angioblast, are precursor of endothelial cells. Under the stimulus of physiological or pathological factors, EPCs mobilize from bone marrow to peripheral blood for participating in the repair of damaged blood vessels. The EPCs play a crucial role in re-endothelialization and repairing the injured endothelium (1). They take part in many diseases, however, there are few EPCs in peripheral blood, and they do not proliferate readily even are dysfunctional (2), so expanding EPCs levels and enhancing EPCs viability may benefit patients. Furthermore, transplantation of EPCs is applied to the treatment of ischemic diseases, but how to optimize the EPCs proliferation and amplification is still a problem.

In the process of stem cell proliferation and differentiation, cell signaling pathways play a regulatory role, especially Notch signaling pathway and Akt signaling pathway. Akt signaling pathway has a close relationship with cell viability and migration. Some studies showed that it was involved in progesterone-induced EPC viability (3). Notch signaling pathway is highly conserved, and plays a key role in neovascularization and angiogenesis process. It participates in progenitor cells differentiation, proliferation (4) and tube formation (5). We 
assumed that the two signaling pathways were involved in the effect of velvet antler (VA) on EPCs.

VA is common and precious medicinal material of traditional Chinese medicine (TCM) which is called Lu Rong in China, and it has been widely used as food supplement or therapeutic drug generally in China, Japan, Russia, New Zealand and Southeast Asia. Many researches have been carried out to study the constituents as well as pharmacology of VA, however, like many TCM supplements, its mechanism has not been clearly interpreted from western viewpoint. VA has an inherent property that is the ability of regeneration that are structural and functional replicates $(6,7)$. It can quickly grows into a tissue which has rich blood vessels, nerves, fur, flesh and blood within 60 days. Some research showed that VA regeneration is a stem cell-based epimorphic regeneration (8), so this property has drawn many scholars' attention and was related with organ grafting and stem cells differentiation (9), but there is rarely research in this filed.

Some studies have revealed that polypeptides and proteins are the main bioactive components of VA (10), promoting neurite outgrowth (11), the proliferation of epidermal cells and NIH3T3 cells (12), enhancing wound healing (13). Therefore, in this study we extracted VA proteins (VA-pro) using freeze-drying technology, water solvent and ultrasonic wave method, and determined the effect of VA-pro on rat bone marrow-derived EPCs, as well as the possibly molecular signaling pathway mechanisms.

\section{Materials and methods}

Velvet antler preparation. Fresh VAs were the fast-growing antlers of 4-year-old male deer (14) (Cervus Nippon Temminck), which was bred in Jilin Province of China. VAs were identified by Professor Chunsheng Liu, the director of the Department of Chinese Medicine Identification at the TCM Institute, Beijing University of Chinese Medicine. Blood was drawn from the VAs with a vacuum instrument for $6 \mathrm{~h}$ in $4^{\circ} \mathrm{C}$. VAs were sliced and freeze-dried by lyophilizer $\left(-60^{\circ} \mathrm{C}\right.$ and $12 \mathrm{~Pa}, \mathrm{LABCONCO}$ ) until quality change was less than $0.1 \mathrm{~g}$. With the superfine grinding technology, freeze-dried VAs were superfinely comminuted in cryogenic environment. $54.08 \mathrm{~g}$ lyophilized VA powder was created, and the dehydration percentage of VA was $67.02 \%$. The powder was stockpiled in sealed tubes and numbered XX-DGF01 to XX-DGF04.

Lyophilized VA powder (XX-DGF01) was mixed with ultrapure water (1:10) and blended through vortex oscillation (5 s/15 s). Using homogenate and immersion methods, the VA was ultrasonically extracted for $2 \mathrm{~h}$ in an ice-bath. The supernate was obtained in a centrifuge tube and the precipitate was removed by centrifugation $(12,000 \mathrm{rpm}, 30 \mathrm{~min})$. The supernate was stored at $-80^{\circ} \mathrm{C}$ for at least $12 \mathrm{~h}$, and then get freeze-dried by the lyophilizer for $72 \mathrm{~h}$. The precipitate was processed according to the above steps for 3 times. All freeze-dried VA-pro were mixed together and were numbered from XX-VApro01 to XX-VApro03, being stored at $-80^{\circ} \mathrm{C}$. The VA-pro mass concentration was $465.56 \mu \mathrm{g} / \mathrm{mg}$, which was measured by a BCA protein assay kit (Thermo Fisher Scientific).

Nano LC-MS/MS analysis. We digested VA-pro with trypsin (30:1) for $24 \mathrm{~h}$ at $37^{\circ} \mathrm{C}$, and the desalinization were taken with
$\mathrm{C}_{18}$ column (Phenomenex Strata ${ }^{\mathrm{TM}}$ ). High performance liquid chromatography (HPLC) was performed and the desalted peptide mixture was separated with a reversed phase $\mathrm{C}_{18}$ column $(75 \mu \mathrm{m} \times 10 \mathrm{~cm}, 5 \mu \mathrm{m}, 300 \AA$ Á, Agela Technologies) at $400 \mathrm{nl} / \mathrm{min}$ constant flow rate. Peptides were eluted with a gradient of $5-80 \%(\mathrm{v} / \mathrm{v})$ and the acetonitrile in $0.1 \%$ formic acid over $65 \mathrm{~min}$. The eluates were directly entered into a Q-Exactive Orbitrap Mass Spectrometer (Thermo Fisher Scientific), which was set in positive ion mode, the scan range was $350-2000 \mathrm{~m} / \mathrm{z}$ and scan resolution was at 17,500. $1 \mathrm{E}+5$ was the minimum signal threshold and isolation width was at $2 \mathrm{Da}$. Ion source voltage was set at $1800 \mathrm{~V}$. $2 \mathrm{MS} / \mathrm{MS}$ acquisition modes and higher collision energy dissociation were employed to evaluate the performance of this MS on the iTRAQ-labeled samples (Fig. 1 The ensample of VA mass spectrometric patterns).

MS data analysis. After Nano LC-MS/MS measurement, the raw data were filtered by the PD (Proteome Discoverer 1.3, Thermo Fisher Scientific). The collected data files were sent to a MASCOT server (Version 2.3.0, Matrix Science) for peptide identification with the Ruminantia (Number of sequences: 93869) taxonomy constraint.

386 VA-pro were identified. Their molecular weight (MW) range and isoelectric point $(\mathrm{pI})$ range were showed in Tables I and II.

EPCs primary culture. Bone marrow-derived mononuclear cells (BM-MNCs) were isolated from 2-week-old male SD rats femur by the density gradient centrifugation method, using lymphocyte separation medium (TBD Science). BM-MNCs were seeded on a $35 \mathrm{~mm}$ culture dish and incubated in complete endothelial basal medium (EBM-2 medium, Lonza) under standard cell culture condition. After $72 \mathrm{~h}$, first medium change was performed, and non-adherent cells were removed, while the adherent cells were continuously cultured for 14 days, then the cells were identified by CD133 (Novus) and VEGFR2 (15) (Abcam).

Immunofluorescence. In order to characterize EPCs, cells were fixed for $15 \mathrm{~min}$ in $4 \%$ paraformaldehyde at room temperature. Then they were deal with $0.3 \%$ triton-100/PBS for $10 \mathrm{~min}$, blocked with $3 \% \mathrm{BSA} / \mathrm{PBS}$ for $1 \mathrm{~h}$. cells were incubated with primary antibodies overnight at $4{ }^{\circ} \mathrm{C}$, followed by immunolabelling with Alexa 488-conjugated secondary antibody $(1: 200, \mathrm{CST})$, for $1 \mathrm{~h}$ at room temperature in the dark. The nuclei were stained by DAPI for $10 \mathrm{~min}$. The cells were imaged and counted under an Inversed Fluorescent Microscope (Nikon). Digital images were prepared using NIS Elements AR Analysis 4.10.00.

Cell proliferation assay. EPCs proliferation was detected with MTS kit (the Cell Titer $96^{\circledR}$ Aqueous One Solution Reagent). EPCs were cultured in 96-well plates with different treatment. Then each well was added $100 \mu 1$ EBM- 2 medium and $20 \mu \mathrm{l}$ reagent and cells were cultured for $3 \mathrm{~h}$. The optical density (OD) was measured by Microplate Spectrophotometer (Spectra MR).

Tubule formation assay. Tubule Formation Assay was determined with Matrigel (BD Biosciences). After thawing for $3 \mathrm{~h}$ 


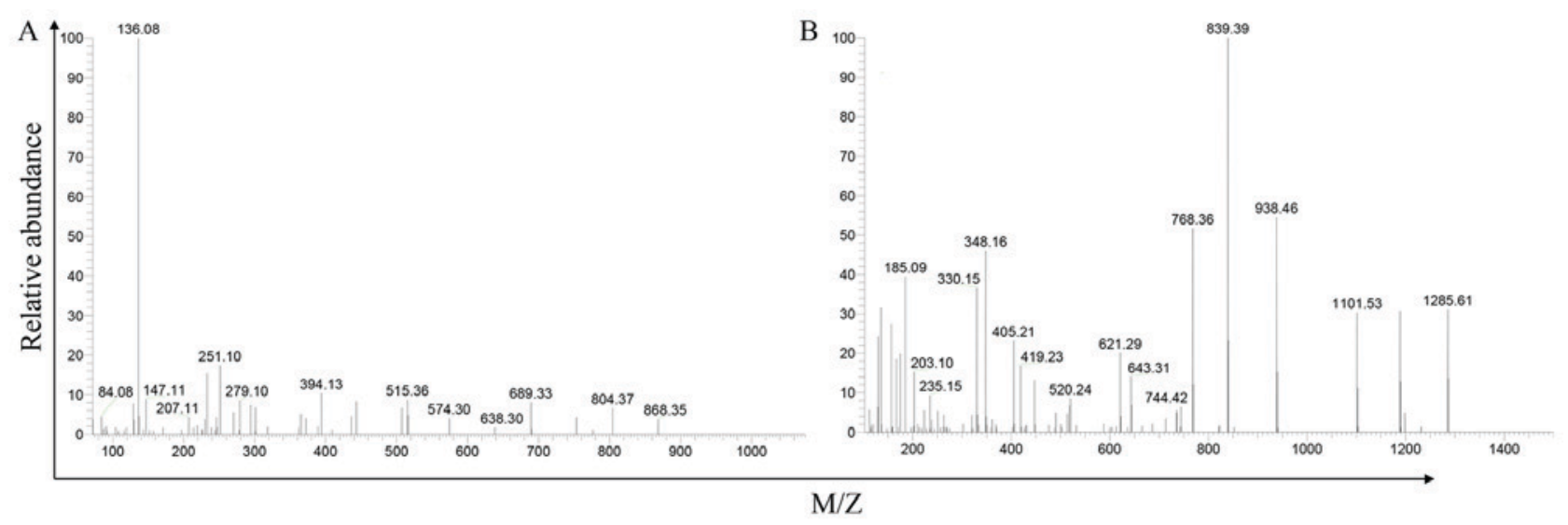

Figure 1. The sample of VA mass spectrometric patterns. (A) Heat shock protein 70.1 and (B) 14-3-3 protein $\beta / \alpha$.

Table I. VA-pro molecular weight.

\begin{tabular}{lccccccccccc}
\hline $\mathrm{MW}(\mathrm{kDa})$ & $<10$ & $10-20$ & $20-30$ & $30-40$ & $40-50$ & $50-60$ & $60-70$ & $70-80$ & $80-100$ & $100-200$ & $>200$ \\
$\mathrm{~N}$ & 5 & 63 & 51 & 46 & 42 & 39 & 24 & 20 & 20 & 49 & 24 \\
\hline
\end{tabular}

Table II. VA-pro isoelectric point.

\begin{tabular}{ccccccccc}
\hline $\mathrm{pI}$ & $4-5$ & $5-6$ & $6-7$ & $7-8$ & $8-9$ & $9-10$ & $10-11$ & $11-12$ \\
$\mathrm{~N}$ & 50 & 128 & 84 & 29 & 49 & 20 & 16 & 7 \\
\hline
\end{tabular}

at $4^{\circ} \mathrm{C}, 100 \mu \mathrm{l}$ Matrigel was added into every well of 48 -well plate and was put into an incubator to solidify for $30 \mathrm{~min}$. $2 \times 10^{4}$ EPCs were seeded on the top of the Matrigel layer and were treated with different concentrations of VA-pro. The net structure was observed under a bright field microscope (Leica Microsystems) within $24 \mathrm{~h}$ and it was calculated in four random fields using NIS Elements AR Analysis 4.10.00.

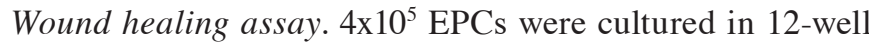
plates for $24 \mathrm{~h}$. The wound was made by scratching confluent cell monolayers with a P200 pipette tip, three parallel 'wounds' were created in each well with floating cells being washed away. After cells were incubated with different treatment, the migrated cells were photographed and the mean distance between the two ends of the scratch was quantified by manual measurements with Prism 5.0 program (GraphPad Inc.).

Transwell assay. Cell transwell assay was performed using invasion chambers (BD Biosciences). $150 \mu \mathrm{l}$ cell suspension (1x10 cells $/ \mathrm{ml}, \mathrm{FBS}$-free medium) was placed to the inserts, while medium containing VA-pro were added to the bottom chamber. After $24 \mathrm{~h}$ culture, the cells still in the upper side of inserts were cleared with cotton swabs and cells that had penetrated through the polyethylene terephthalate membrane were fixed and stained using mounting medium with DAPI (ZSGB-BIO). The cells were counted in 10 random microscopic fields.

Western blotting. Treated cells were washed and lysed with RIPA lysis buffer, containing PMSF (Beyotime) and phosphatase inhibitors (sigma-Aldrich). Protein concentration was detected using a bicinchoninic acid protein assay kit (BCA, Thermo Fisher Scientific). Proteins were separated on $8 \%$ polyacrylamide gel SDS-PAGE for $110 \mathrm{~min}$ (Notch1, NICD, mTOR and p-mTOR) or $12 \%$ polyacrylamide gel SDS-PAGE for $50 \mathrm{~min}$ (Hes1, Akt and p-Akt), and they were transferred to a nitrocellulose membrane using $350 \mathrm{~mA}$ for $50 \mathrm{~min}$ (Hes1, Akt and p-Akt) or $3.5 \mathrm{~h}$ (Notch1, NICD, mTOR and p-mTOR). Membranes were blocked with 5\% nonfat dry milk and washed with PBS. Then they were cut into 3 sections according to markers. Each section of membrane was incubated overnight at $4^{\circ} \mathrm{C}$ with the antibodies against Notch1, NICD, Hes1, Akt, p-Akt, mTOR, p-mTOR or $\beta$-actin (CST, 1:1,000). Membranes were then washed and further incubated for $1 \mathrm{~h}$ at $37^{\circ} \mathrm{C}$ with goat anti-mouse $\operatorname{IgG}$ or goat anti-rabbit $\operatorname{IgG}$ antibody (1:5,000, Santa cruz), which conjugated with HRP and was diluted in TBST containing 5\% nonfat dry milk. Membranes were soaked with super ECL plus (1:1, Millipore) and wrapped with plastic wrap in the dark. The results were detected by an ECL luminescent detection system. Band density was analyzed using Image-Pro Plus 6.0 (Media Cybernetics).

Statistics. Experiments were repeated at least three times. Quantitative Data were presented as means \pm SD and were analyzed using SPSS 17.0 software by ANOVA followed by Tukey's or Dunnett's posttest. $\mathrm{P}<0.05$ was considered as significant.

\section{Results}

EPCs characterization. EPCs were cultured from rat bone marrow for 7 days, the adherent cells were active and colonies were appeared (Fig. 2A, B). The cells potential to form tubes was tested (Fig. 2C). The stem cell marker CD133 and surface marker VEGFR2 were positive (Fig. 2D). All above manifested that BM-MNCs were induced into EPCs successfully. 
A

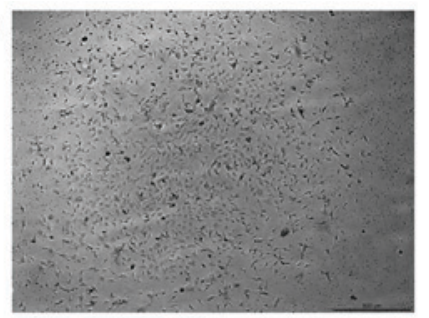

$\mathrm{D} \mathrm{CD} 133$
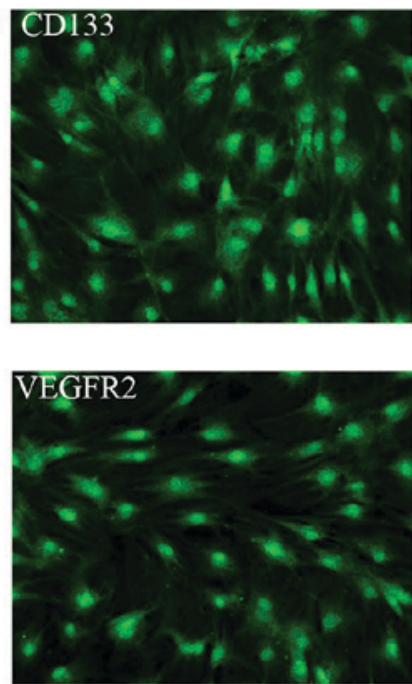

B

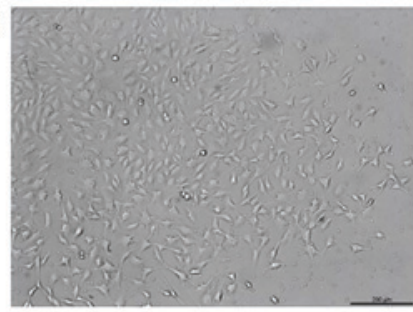

DAPI

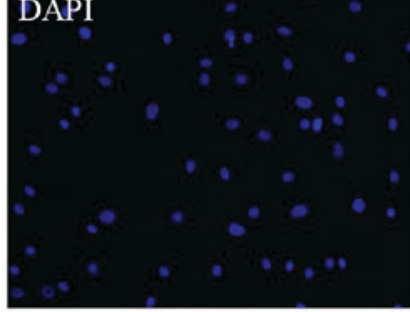

DAPI

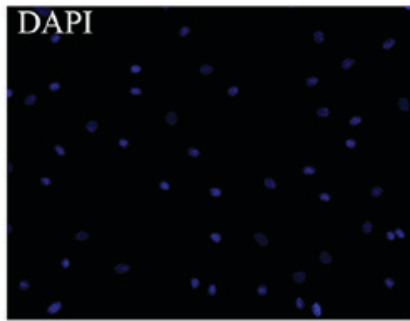

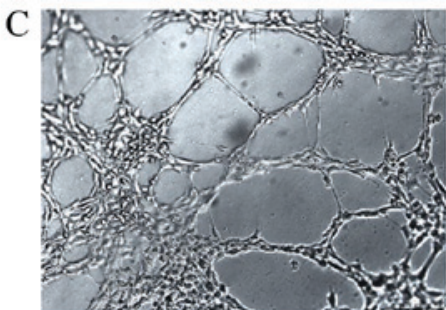
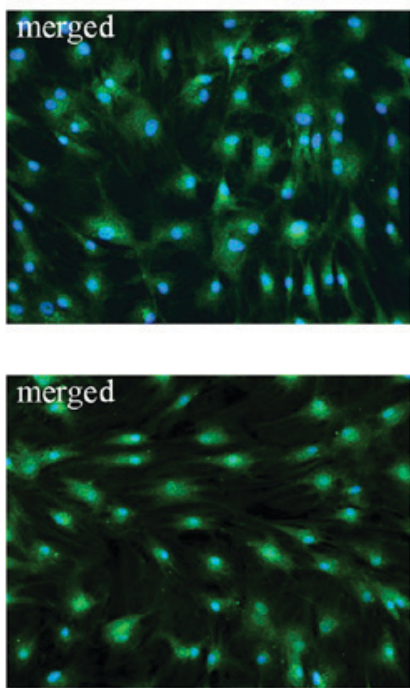

Figure 2. Characterization of EPCs. EPCs colonies appeared after 7 days culture (A, magnification: x50, Scale Bar: 500 $\mu$ m; B, magnification: x100, Scale Bar: $200 \mu \mathrm{m})$. EPCs tube formation was assessed with Matrigel (C, magnification: x100, Scale Bar: $200 \mu \mathrm{m})$. Representative immunofluorescence staining of EPCs markers including CD133 and VEGFR2 were positive, cell nuclei were stained with DAPI (D, magnification: x200, Scale Bar: 100 $\mu$ m).
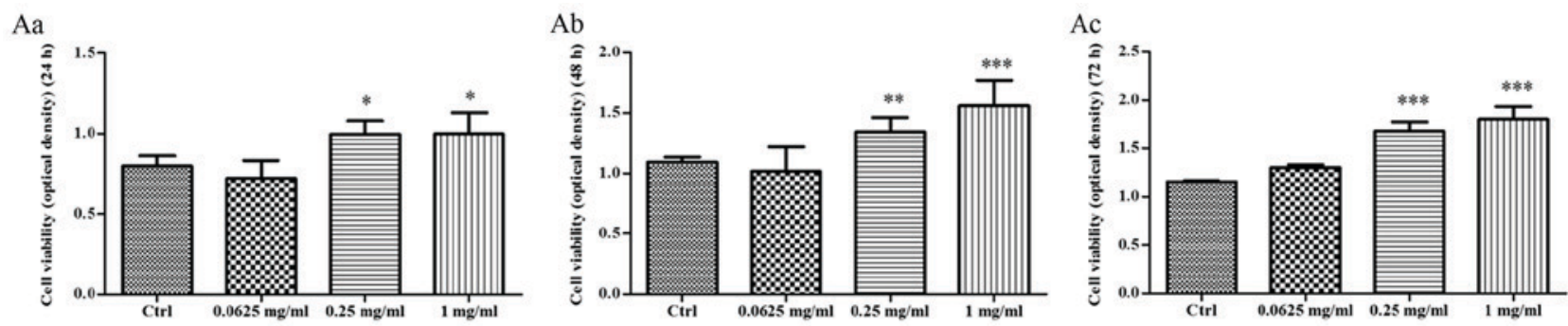

$\mathrm{Ba}$

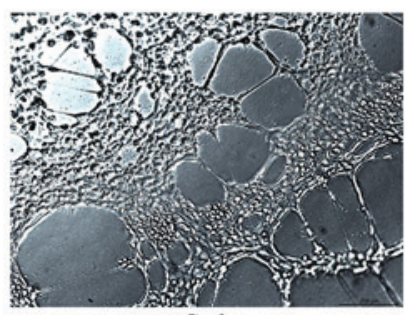

Ctrl

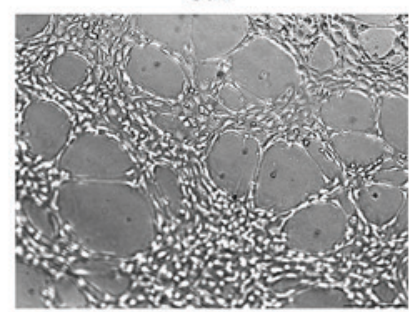

$0.25 \mathrm{mg} / \mathrm{ml}$
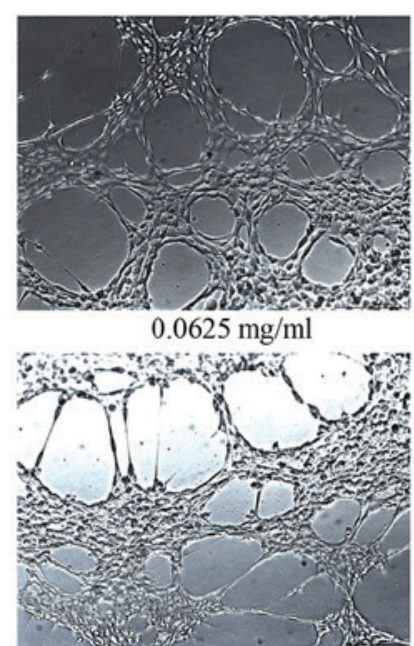

$1 \mathrm{mg} / \mathrm{ml}$
$\mathrm{Bb}$

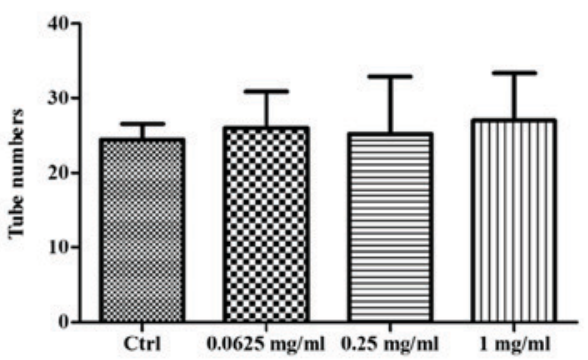

Figure 3. VA-pro promoted EPCs proliferation, but had no effect on EPCs ability of tube formation. Proliferation was detected using MTS kit at $24 \mathrm{~h}$ (Aa), $48 \mathrm{~h}$ $(\mathrm{Ab})$ and $72 \mathrm{~h}(\mathrm{Ac})$, respectively. OD was measured by microplate spectrophotometer. The net structure of tube formation assay was observe under bright field microscope (Ba, magnification: $x 100$, Scale Bar: $200 \mu \mathrm{m}$ ). Data were presented as mean $\pm \mathrm{SD},{ }^{*} \mathrm{P}<0.05,{ }^{* *} \mathrm{P}<0.01$ and ${ }^{* * * *} \mathrm{P}<0.001$ compared to the control group. 
Aa

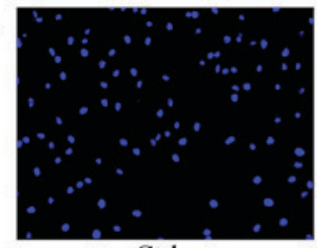

Ctrl

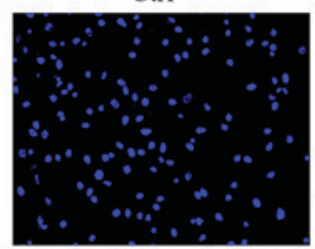

$0.25 \mathrm{mg} / \mathrm{ml}$

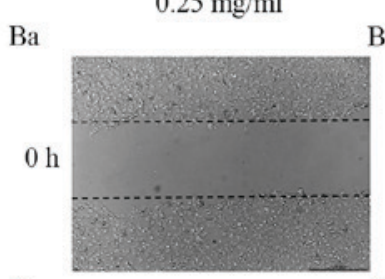

Be

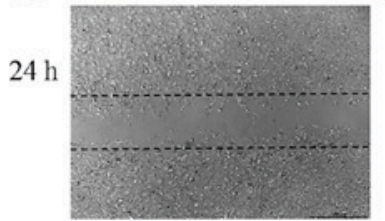

Bi

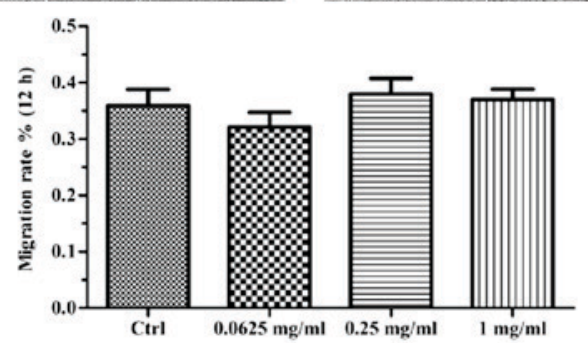

Bk

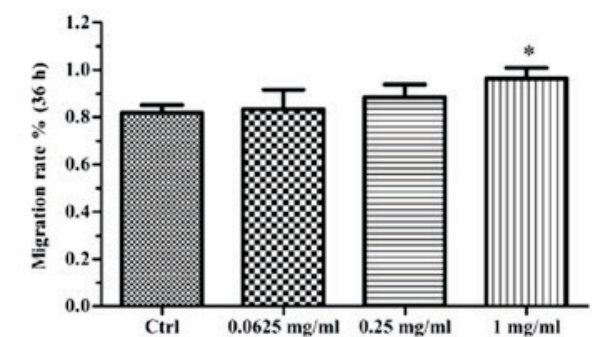

$\mathrm{Ab}$

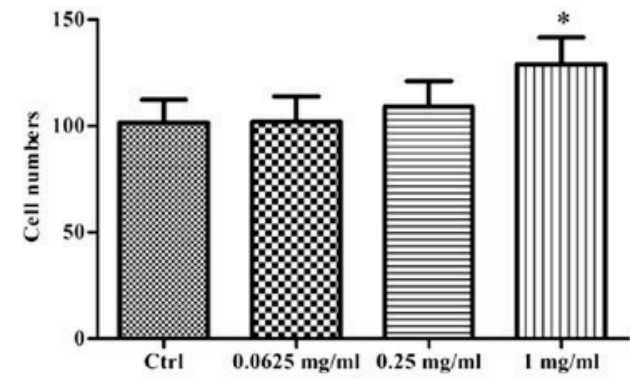

$\mathrm{Bc}$

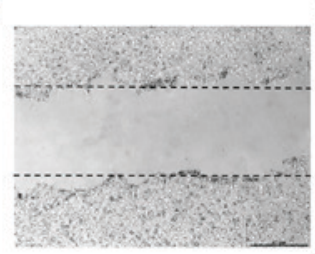

$\mathrm{Bd}$

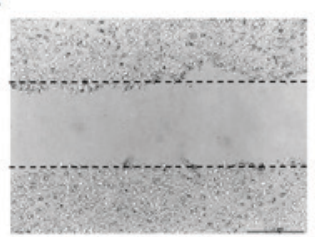

$\mathrm{Bh}$
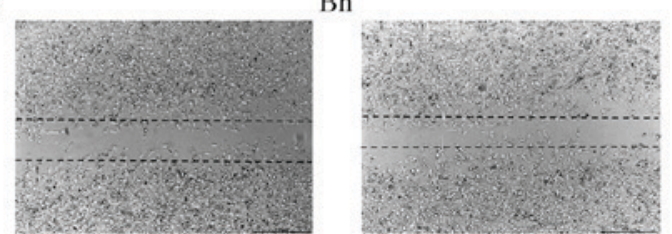

$\mathrm{Bj}$

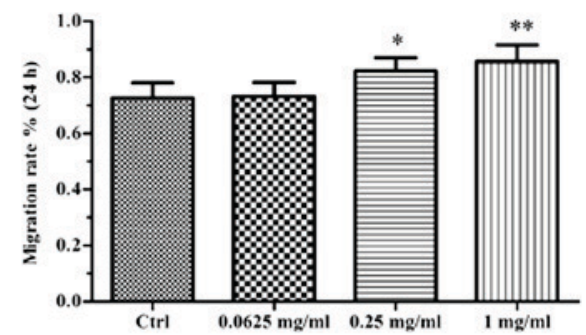

Bl

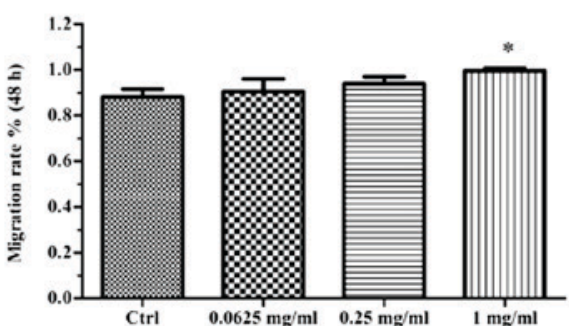

Figure 4. The migration of EPCs treated with $1 \mathrm{mg} / \mathrm{ml}$ VA-pro was different from the control group in transwell assay (A). Cells that had penetrated through the polyethylene terephthalate membrane were stained with DAPI and counted in 10 random microscopic fields (Aa, magnification, x200, Scale Bar: $100 \mu \mathrm{m}$ ). After scratched, EPCs were photograph every $12 \mathrm{~h}$, we choose the photos of $24 \mathrm{~h}$ to show here (Ba-h) (magnification: x50, Scale Bar: $500 \mu \mathrm{m}$ ). The average width of scratches was measured and the EPCs migration rate was calculated, Data were presented as mean $\pm \mathrm{SD},{ }^{*} \mathrm{P}<0.05$ and ${ }^{* *} \mathrm{P}<0.01$ compared to the control group.

The effect of VA-pro on EPCs proliferation, tube formation. EPCs of the control group were cultured in complete EBM-2 medium, while cells in other groups were cultured with 0.0625 , 0.25 and $1 \mathrm{mg} / \mathrm{ml} \mathrm{VA-pro.} \mathrm{We} \mathrm{detected} \mathrm{the} \mathrm{cells} \mathrm{proliferation}$ at 24,48 and $72 \mathrm{~h}$, respectively. 0.25 and $1 \mathrm{mg} / \mathrm{ml} \mathrm{VA-pro} \mathrm{treat-}$ ment resulted in a promoting of EPCs proliferation in different degree at 3 time points, cell proliferation of $0.0625 \mathrm{mg} / \mathrm{ml}$ group has no difference compared with the control group (Fig. 3Aa, b, c). These data suggested that VA-pro can promote EPCs proliferation. A Matrigel tube formation assay was used to evaluate the effect of VA-pro on EPCs tube formation. As shown in Fig. 3Ba-b, VA-pro had no effect on EPCs ability of tube formation.

The effect of VA-pro on EPCs migration. For transwell assay, after cultured for $24 \mathrm{~h}$, the migration of EPCs treated with $1 \mathrm{mg} / \mathrm{ml} \mathrm{VA-pro} \mathrm{was} \mathrm{different} \mathrm{from} \mathrm{the} \mathrm{control} \mathrm{group} \mathrm{(Fig.} \mathrm{4Aa).}$ These data indicated that VA-pro promoted the migration of EPCs, especially the $1 \mathrm{mg} / \mathrm{ml}$ concentration (Fig. 4Ab). For the wound healing assay, after scratched the confluent cell 
A

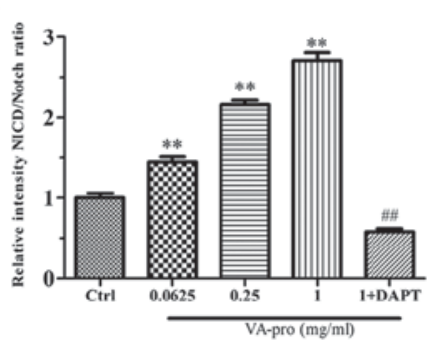

$\mathrm{C}$

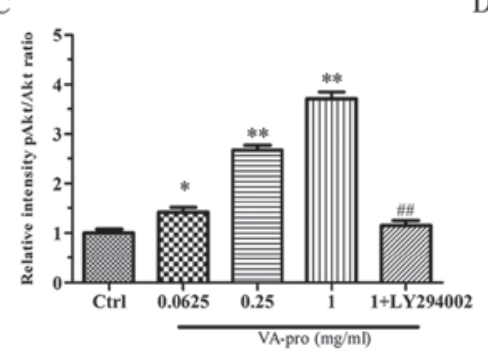

B

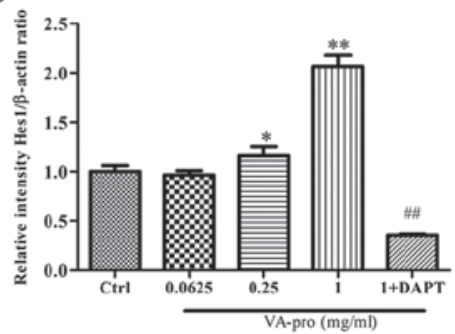

$\mathrm{D}$

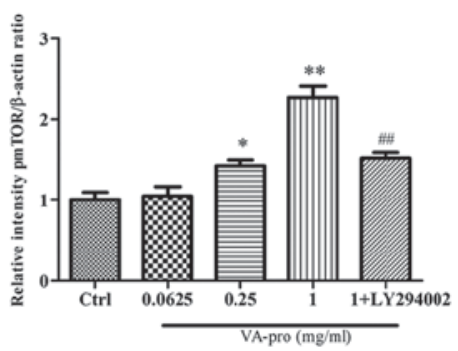

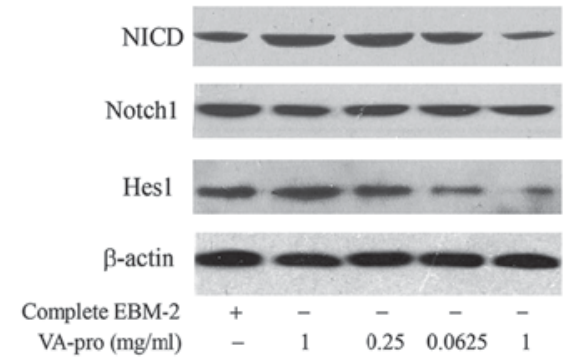

DAPT

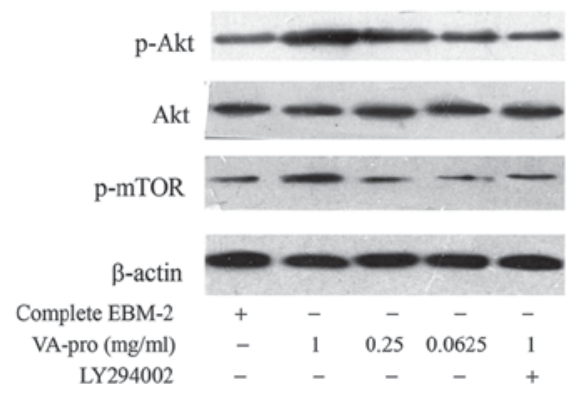

Figure 5. VA-pro can increase the activation level of Notch1 and Hes1 as well as the level of p-Akt and p-mTOR in EPCs. The activation level of NICD concentration-dependently increased along with VA-pro treatment (A), and Hes1 activation level also significantly increased (B). However, Notch1 pathway inhibitor (DAPT, $10 \mu \mathrm{M}$ ) inversed the results. Compared to the control group, the level of p-Akt concentration-dependently increased along with VA-pro (C), and p-mTOR level also increased significantly (D). However Akt pathway inhibitor (LY294002, $10 \mu \mathrm{M}$ ) suppressed the effects of VA-pro on p-Akt and p-mTOR expression. Data were presented as mean $\pm \mathrm{SD},{ }^{*} \mathrm{P}<0.05$ and ${ }^{* *} \mathrm{P}<0.01$ compared to the control group, ${ }^{\# \#} \mathrm{P}<0.01$ compared to the VA-pro $1 \mathrm{mg} / \mathrm{ml}$ group.

monolayers, EPCs were photograph every $12 \mathrm{~h}$, the average width of scratches was measured and the EPCs migration rate was calculated. Results showed that $1 \mathrm{mg} / \mathrm{ml} \mathrm{VA-pro} \mathrm{treatment}$ led to better cell migration at 24,36 and $48 \mathrm{~h}$ compared to the control group. Besides, $0.25 \mathrm{mg} / \mathrm{ml}$ VA-pro caused a significant difference compared to the control group only at $24 \mathrm{~h}$ (Fig. 4Bi-l). We chose the photos at the time of $24 \mathrm{~h}$ to show the differences between groups (Fig. 4Ba-h).

Effect of VA-pro on the activation level of Notch and Hesl, and the phosphorylation level of Akt and mTOR in EPCs. Notch1 pathway inhibitor DAPT $(10 \mu \mathrm{M})$ and Akt pathway inhibitor LY294002 $(10 \mu \mathrm{M})$ were added to the medium containing $1 \mathrm{mg} / \mathrm{ml} \mathrm{VA-pro.} \mathrm{As} \mathrm{shown} \mathrm{in} \mathrm{Fig.} \mathrm{5,} \mathrm{there} \mathrm{was}$ no obvious differences in the total amount of Notch1, but the activation level of Notch1 Intracellular Domain (NICD) significantly increased along with VA-pro stimulation concentration-dependently, and Hes1 activation level also significantly increased. However DAPT inversed all. The ratio of NICD to the total Notch1 and Hes1 to the $\beta$-actin were calculated to evaluate the activation of Notch1 and Hes1 (Fig. 5A, B).

Compared to the control group, VA-pro increased the phosphorylation level of Akt in a concentration-dependent manner, and mTOR phosphorylation level also significantly increased. However LY294002 inversed this outcome, it suppressed the effects of VA-pro on p-Akt and p-mTOR expression (Fig. 5C, D).

These indicated that VA-pro affected EPCs possibly through activating the Notch pathway and Akt/mTOR pathway.

\section{Discussion}

EPC has been researched as a hotspot in recent years, not only has it been linked to the development of many diseases, but plays a key role in treating certain diseases. EPCs have been engaged to replace damaged endothelial cells and increase neovascularization in many animal models $(16,17)$.

Whether stem cells transplantation is more good than harm or not has been controversial, but some researches show that stem cells have good curative effects on the treatment of diseases. Better applications of this method are worth to be explored. Chen et al transplanted autologous EPCs into cerebral ischemia rabbits models, after 14 days, most of EPCs binded to UEA-1 lectin were incorporated into capillaries, resulting in an increase of microvascular density in the ischemia area, the infarction area reducing and brain function improving (18). Other research (19) has shown that for MODS pigs, autologous transplantation of EPCs migrated to the injured organs and induced angiogenesis for replying the blood supply of vital organs as well as improving their function. Furthermore, the clinical research about therapeutic angiogenesis by cell transplantation (TACT) reported that doctors injected the peripheral mononuclear cells which were collected from patient's right subclavian vein into local muscle for the treatment of ulcer causing by occlusive arterial sclerosis, the patient's general condition was not good and other treatment no curative effect on ulcer. 2 weeks postoperative, skin temperature increased. 1 month later, ulcer's blood flow improved and the ulcer completely healed by 6 months later. This suggested that transplantation may offer a suitable alternative rescue therapy for patients with critical limb ischemia (20). Earlier, a TACT program in Japan was also succeeded in 2003, the research about allogeneic EPCs transplantation also suggested that EPCs transplantation was very effective on vascular diseases. Meanwhile, it indicated that EPCs immunogenicity was not very high.

Now, how to optimize the EPCs proliferation and amplification is a great task for transplantation. Many scholars try 
to make the EPCs culture system better. They have tried to use autologous serum (21), autologous culture system (22) and osteopontin (23). Therefore, this filed is interesting and ponderable. In our experiment, we used the freeze-drying technology for better maintenance of proteins biological activity, VA-pro was extracted by water solvent and ultrasonic wave method (24). The experimental results provided that VA-pro can promote EPCs proliferation and migration.

Notch signaling pathway promotes proliferative signaling ways during neurogenesis and gets involved in heart development, neovascularization and angiogenesis process $(25,26)$. The key link of Notch1 signaling pathway is the activation of Notch1 Intracellular Domain (NICD). Notch1 combines with the ligands, and then NICD is releaseed into the cytoplasm and gets into nucleus, it binds to CSL (C-promoter binding protein-1, CBF-1) and a complex is formed to activate the genes of transcription inhibitory factor family, such as Hes, Hey or Herp (27). To be expected, it is related to EPCs proliferation, differentiation (4) and tube formation (5). EPCs activity reduces when Notch mRNA is inhibited (28). Hes1 is the direct downstream target of Notch signaling pathway and plays an essential role in the development of blood vessel and heart, etc. Our data revealed that the level of activatory NICD and Hes1 were increased after intervention with VA-pro, which suggested that Notch signaling pathway may be involved in the promoting effect of VA-pro on EPCs proliferation and migration. Akt/mTOR signaling pathway is directly related to cell proliferation, quiescence and longevity via regulating the cell cycle. One research showed that it was involved in progesterone-induced EPC viability (3). Interestingly, VA-pro elevated the phosphorylation level of Akt and mTOR in our research. Thus, the effect of VA-pro on EPCs may be associated with the Akt/mTOR signaling pathway.

Actually, there is much crosstalk between Notch and Akt signaling pathways $(29,30)$. Previous studies on Notch and Akt signaling pathway suggested that Notch signaling pathway could stimulate the Akt signaling pathway by decreasing PTEN (phosphatase and tensin homology deleted on chromosome 10) levels (31). PTEN can stop all downstream effects of Akt signaling pathway by reducing the AKT activation, and it affects a variety of cellular functions widely. Hes1 can inhibit PTEN effectively via binding to its promoter, PTEN transcription will increase when shRNA silence of Hes1 is performed $(31,32)$.

Interactions between Notch and Akt signaling pathways provide the basis for the similar results of NICD, Hes1, p-Akt and p-mTOR affected by VA-pro in this study, Research of the signaling pathway in this study just remind a possible molecular mechanism of VA-pro on EPCs, but it assists our main purpose, which is to find the effective components of VA-pro preferably. We aim to prove that VA-pro really work on EPCs primarily, and then we confirm the effective components of VA-pro gradually, based on VA characteristic of regeneration and in the hope of subsequent artificial extraction or synthetic.

\section{Acknowledgements}

This work was supported by the National Natural Science Foundation of China (grant no. 81573777) and Beijing National Science Foundation (grant no. 7162172).

\section{References}

1. Miller-Kasprzak E and Jagodziński PP: Endothelial progenitor cells as a new agent contributing to vascular repair. Arch Immunol Ther Exp (Warsz) 55: 247-259, 2007.

2. Herbrig K, Haensel S, Oelschlaegel U, Pistrosch F, Foerster S and Passauer J: Endothelial dysfunction in patients with rheumatoid arthritis is associated with a reduced number and impaired function of endothelial progenitor cells. Ann Rheum Dis 65: 157-163, 2006.

3. Yu P, Zhang Z, Li S, Wen X, Quan W, Tian Q, Chen J, Zhang J and Jiang R: Progesterone modulates endothelial progenitor cell (EPC) viability through the CXCL12/CXCR4/PI3K/Akt signalling pathway. Cell Prolif 49: 48-57, 2016.

4. Cortegano I, Melgar-Rojas P, Luna-Zurita L, Siguero-Álvarez M, Marcos MA, Gaspar ML and de la Pompa JL: Notch1 regulates progenitor cell proliferation and differentiation during mouse yolk sac hematopoiesis. Cell Death Differ 21: 1081-1094, 2014.

5. Karcher JR, Hoffmann BR, Liu P, Liu Y, Liang M and Greene AS: Genome-wide epigenetic and proteomic analysis reveals altered Notch signaling in EPC dysfunction. Physiol Rep 3: pii:e12358, 2015.

6. Price J, Faucheux C and Allen S: Deer antlers as a model of mammalian regeneration. Curr Top Dev Biol 67: 1-48, 2005.

7. Price JS, Allen S, Faucheux C, Althnaian T and Mount JG: Deer antlers: A zoological curiosity or the key to understanding organ regeneration in mammals? J Anat 207: 603-618, 2005.

8. Li C, Zhao HP, Liu Z and McMahon C: Deer antler-a novel model for studying organ regeneration in mammals. Int J Biochem Cell Biol 56: 111-122, 2014.

9. Li C, Pearson A and McMahon C: Morphogenetic mechanisms in the cyclic regeneration of hair follicles and deer antlers from stem cells. Biomed Res Int 2013: 643601, 2013.

10. Sui Z, Zhang L, Huo Y and Zhang Y: Bioactive components of velvet antlers and their pharmacological properties. J Pharm Biomed Anal 87: 229-240, 2014.

11. Pita-Thomas W, Nieto-Sampedro M, Maza RM and Nieto-Diaz M: Factors promoting neurite outgrowth during deer antler regeneration. J Neurosci Res 88: 3034-3047, 2010.

12. Guan SW, Duan LX, Li YY, Wang BX and Zhou QL: A novel polypeptide from Cervus nippon Temminck proliferation of epidermal cells and NIH3T3 cell line. Acta Biochim Pol 53: 395-397, 2006.

13. Zha E, Gao S, Pi Y, Li X, Wang Y and Yue X: Wound healing by a $3.2 \mathrm{kDa}$ recombinant polypeptide from velvet antler of Cervus nippon Temminck. Biotechnol Lett 34: 789-793, 2012.

14. Jeon B, Kim S, Lee S, Park P, Sung S, Kim J and Moon S: Effect of antler growth period on the chemical composition of velvet antler in sika deer (Cervus nippon). Mamm Biol 5: 374-380, 2009.

15. Dong Y, Sun Q, Liu T, Wang H, Jiao K, Xu J, Liu X, Liu H and Wang W: Nitrative stress participates in endothelial progenitor cell injury in hyperhomocysteinemia. PLoS One 11: e0158672, 2016.

16. Xue S, Zhang HT, Zhang P, Luo J, Chen ZZ, Jang XD and $\mathrm{Xu}$ RX: Functional endothelial progenitor cells derived from adipose tissue show beneficial effect on cell therapy of traumatic brain injury. Neurosci Lett 473: 186-191, 2010.

17. Fan Y, Shen F, Frenzel T, Zhu W, Ye J, Liu J, Chen Y, Su H, Young WL and Yang GY: Endothelial progenitor cell transplantation improves long-term stroke outcome in mice. Ann Neurol 67: 488-497, 2010.

18. Chen ZZ, Jiang XD, Zhang LL, Shang JH, Du MX, Xu G and Xu RX: Beneficial effect of autologous transplantation of bone marrow stromal cells and endothelial progenitor cells on cerebral ischemia in rabbits. Neurosci Lett 445: 36-41, 2008.

19. Tianhang L, Bo W, Zhengmao L, Tao P, Hong Z, Xuchao X, Jianwei B, Hui Z and Guoen F: Autologous transplantation of endothelial progenitor cells to prevent multiple organ dysfunction syndromes in pig. J Trauma Acute Care Surg 74: 508-515, 2013.

20. Sugihara S, Yamamoto Y, Matsubara K, Ishida K, Matsuura T, Ando F, Igawa G, Narazaki G, Miake J, Tajima F, et al: Autoperipheral blood mononuclear cell transplantation improved giant ulcers due to chronic arteriosclerosis obliterans. Heart Vessels 21: 258-262, 2006.

21. Shumiya T, Shibata R, Shimizu Y, Ishii M, Kubota R, Shintani S and Murohara T: Evidence for the therapeutic potential of ex vivo expanded human endothelial progenitor cells using autologous serum. Circ J 74: 1006-1013, 2010. 
22. Moon SH, Kim SM, Park SJ, Kim H, Bae D, Choi YS and Chung HM: Development of a xeno-free autologous culture system for endothelial progenitor cells derived from human umbilical cord blood. PLoS One 8: e75224, 2013.

23. Vaughan EE, Liew A, Mashayekhi K, Dockery P, McDermott J, Kealy B, Flynn A, Duffy A, Coleman C, O'Regan A, et al: Pretreatment of endothelial progenitor cells with osteopontin enhances cell therapy for peripheral vascular disease. Cell Transplant 21: 1095-1107, 2012.

24. Zhang M, Zhao Y, Li Q and Shen M: Extraction and immune activity of soluble proteins from velvet antler of Cervus nippon Temminck. J Northeast Fore Univ 42: 158-163, 2014.

25. Niessen K and Karsan A: Notch signaling in cardiac development. Circ Res 102: 1169-1181, 2008.

26. de la Pompa JL: Notch signaling in cardiac development and disease. Pediatr Cardiol 30: 643-650, 2009.

27. Paola R, Lucio M and Roberto F: The Notch pathway: A crossroad between the life and death of the endothelium. Eur Heart J 34: 2504-2509, 2013.

28. Ii M, Takeshita K, Ibusuki K, Luedemann C, Wecker A, Eaton E, Thorne T, Asahara T, Liao JK and Losordo DW: Notch signaling regulates endothelial progenitor cell activity during recovery from arterial injury in hypercholesterolemic mice. Circulation 121: 1104-1112, 2010.
29. Cornejo MG, Mabialah V, Sykes SM, Khandan T, Lo Celso C, Lopez CK, Rivera-Muñoz P, Rameau P, Tothova Z, Aster JC, et al: Crosstalk between NOTCH and AKT signaling during murine megakaryocyte lineage specification. Blood 118: 1264-1273, 2011.

30. Liu ZJ, Xiao M, Balint K, Soma A, Pinnix CC, Capobianco AJ, Velazquez OC and Herlyn M: Inhibition of endothelial cell proliferation by Notch1 signaling is mediated by repressing MAPK and PI3K/Akt pathways and requires MAML1. FASEB J 20: 1009-1011, 2006.

31. Palomero T, Sulis ML, Cortina M, Real PJ, Barnes K, Ciofani M, Caparros E, Buteau J, Brown K, Perkins SL, et al: Mutational loss of PTEN induces resistance to NOTCH1 inhibition in T-cell leukemia. Nat Med 13: 1203-1210, 2007.

32. Palomero T, Dominguez $M$ and Ferrando AA: The role of the PTEN/AKT pathway in NOTCH1-induced leukemia. Cell Cycle 7: 965-970, 2008. 